\title{
16
}

\section{Coevolutionary Dynamics and the Conservation of Mutualisms}

\author{
Judith L. Bronstein, Ulf Dieckmann, and Régis Ferrière
}

\subsection{Introduction}

The vast majority of studies in conservation biology focus on a single species at a time. However, many of the anthropogenic threats that species face occur via disrupted or enhanced interactions with other organisms. According to one recent analysis, interactions with introduced species, such as predators, parasites, and pathogens, are the eighth leading cause of species endangerment worldwide; they are the primary cause of endangerment in Hawaii and Puerto Rico (Czech and Krausman 1997). Altering interactions not only has ecological effects, but also it can generate selective pressures and evolutionary responses, which may either favor or disfavor the evolutionary persistence of species and interactions. An increased focus on interspecific interactions will thus enlighten our efforts to conserve species and, more pointedly, our ability to understand when species will and will not respond evolutionarily to conservation threats. Such a focus is also critical for efforts to conserve communities as units, because interactions are the crucial and poorly understood link between threatened species and threatened species assemblages.

Different types of interspecific interactions are subject to, and generate, somewhat different ecological and evolutionary threats. Predator and pathogen introductions can lead to reduction, local exclusion, or extinction of native species (Savidge 1987; Schofield 1989; Kinzie 1992; Steadman 1995; Louda et al. 1997). Rapid evolution in the enemies and/or the victims may also result (Dwyer et al. 1990; Singer and Thomas 1996; Carroll et al. 1998). Conversely, the disappearance of enemies (or the introduction of a species into a habitat that lacks enemies) can have consequences that extend across the population, community, and ecosystem (Thompson 1996; Fritts and Rodda 1998). The effects of altering competitive interactions appear to be qualitatively similar, although smaller in magnitude (Simberloff 1981; Williamson 1996). Introducing competitors can reduce populations of native species, with the possible effects being local exclusion, extinction, or evolutionary change of one or both species (Schofield 1989; Moulton 1993; Cohen 1994; Dayan and Simberloff 1994).

Antagonistic interactions have been relatively well studied from the evolutionary, ecological, and conservation perspectives. In contrast, our understanding of mutualisms - interactions that are mutually beneficial to both species (Box 16.1) is at a much earlier stage of development (Bronstein 1994, 2001a). The ecological 
Box 16.1 Mutualistic interactions

Mutualisms are interspecific interactions in which each of two partner species receives a net benefit. Well-known examples include interactions between plants and mycorrhizal fungi, plants and pollinators, animals and gut bacteria, and corals and zooxanthellae (Herre et al. 1999; Bronstein 2001a). Mutualisms generally involve the exchange of commodities in a "biological market": each species trades a commodity to which it has ready access for a commodity that is difficult or impossible for it to acquire (Noë and Hammerstein 1995; see also Douglas 1994). For instance, plants provide carbon to their mycorrhizal fungi in return for phosphorus, and plants provide nectar to many animals in return for pollen transport. Although a great deal is known about the natural history of diverse mutualisms, relatively little effort has yet been invested in the study of ecological and evolutionary similarities among them (Bronstein 1994). This is particularly surprising in light of their perceived importance in nature. All organisms are currently believed to associate with mutualistic species at some point in their lives. Furthermore, mutualisms are thought to lie at the core of major transitions in the history of life, including the origin of the eukaryotic cell and the invasion of land.

To understand mutualism in an evolutionary conservation context, it is important to distinguish it from related phenomena with which it is often confused. Mutualism is an association between different species; it involves somewhat different evolutionary forces and poses different conservation challenges than does cooperation within species (Dugatkin 1997). Not all mutualisms are symbioses (intimate physical associations; Douglas 1994); many involve free-living organisms that associate for only part of their lives. Free-living organisms are likely to be vulnerable to somewhat different anthropogenic threats, which raises the interesting problem of how these mutualisms persist when one, but not both, of the partners is at risk. Conversely, not all symbioses are mutualistic. Hence, this chapter does not consider how anthropogenic change might affect the evolution of diseases (which are antagonistic symbioses). Finally, not all mutualisms have long evolutionary or coevolutionary histories. For instance, pairs of invasive species can sometimes form highly successful mutualisms (Simberloff and von Holle 1999). Evolution may well occur after the association has formed, however (Thompson 1994). Such evolution can change the specificity of the interaction (from more specialized to more generalized, or vice versa), as well as its outcome (from mutualistic to antagonistic, or vice versa).

The large majority of mutualisms are rather generalized: each species can obtain the commodities it requires from a wide range of partner species (Waser et al. 1996; Richardson et al. 2000). Furthermore, many mutualisms are facultative, in the sense that at least some of the commodity can be obtained from abiotic sources. However, many extremely specialized mutualisms do exist: they are species-specific (i.e., there is only a single mutualist species that can provide the necessary commodity), and may be obligate as well (i.e., individuals cannot survive or reproduce in the absence of mutualists). Box 16.3 provides details of one such specialized mutualism. Note that the degree of specificity is not necessarily symmetrical within a mutualism. For instance, many orchid species can be pollinated by a single species of orchid bee, whereas these bee species visit many different orchids, as well as other plants (Nilsson 1992). The evolutionary flexibilities that result from these asymmetries in specificity remain almost entirely unexplored. 
effects of disrupting mutualism are known from only a handful of case studies, which have largely involved a single form of mutualism, plant-pollinator interactions (see the excellent reviews by Bond 1994, 1995; Allen-Wardell et al. 1998; Kearns et al. 1998). The evolutionary consequences of such disruptions remain virtually unexplored. This gap in knowledge is of particular concern because mutualisms are now believed to be a focus around which diversity accumulates, on both ecological and evolutionary time scales (e.g., Dodd et al. 1999; Wall and Moore 1999; Bernhard et al. 2000; Smith 2001).

We begin this chapter with a discussion of processes that foster the ecological and evolutionary persistence of mutualisms. We go on to discuss the sequence of events that can endanger species that depend on mutualists, in the context of some prominent forms of anthropogenic change. With this background, we outline three scenarios for the possible outcomes when the mutualists of a species of interest become rare - linked extinction, ecological resilience, and evolutionary response - and distinguish the likelihood of each outcome based on whether the mutualism is relatively specialized or generalized. As we show, simple evolutionary models can generate quite useful predictions relevant to the conservation of mutualisms and other species interactions. Furthermore, we show that modeling pairwise associations can form an excellent first step toward addressing the fascinating, but much less tractable, problem of coevolution at the community scale.

\subsection{Factors that Influence the Persistence of Mutualisms}

The persistence of mutualisms has long been a puzzle. From the ecological perspective, the positive feedback inherent to mutualisms led May (1976) to characterize mutualisms as an unstable "orgy of mutual benefaction". Yet, at the same time, dependence on mutualists also raises the likelihood of Allee effects (see Chapter 2), in which the low abundance of one species can doom its partner to extinction. From the evolutionary perspective, the major threat to mutualism is the apparent selective advantage that accrues to individuals who reap benefits from partner species without investment in costly commodities to exchange with them (Axelrod and Hamilton 1981; Soberon Mainero and Martinez del Rio 1985; Bull and Rice 1991; Bronstein 2001b). Slight cheats that arise by mutation could gradually erode the mutualistic interaction, and lead to dissolution or reciprocal extinction (Roberts and Sherratt 1998; Doebeli and Knowlton 1998). Although cheating has been assumed to be under strict control, recent empirical findings (reviewed by Bronstein 2001b) indicate that cheating is rampant in most mutualisms; in some cases, cheaters have been associated with mutualisms over long spans of evolutionary time (Després and Jaeger 1999; Pellmyr and Leebens-Mack 1999; Lopez-Vaamonde et al. 2001). Recent theoretical advances have increased our understanding of the ecological and evolutionary persistence of particular forms of mutualism (e.g., Holland and DeAngelis 2001; Law et al. 2001; Yu 2001; Holland et al. 2002; Morris et al. 2003; Wilson et al. 2003).

Below, we introduce and discuss a simple general model to describe the ecological and evolutionary dynamics of a two-species, obligate mutualism in a constant 
Box 16.2 Ecology and evolution of specialized mutualisms: a simple model

We describe the obligate and specialized mutualistic interaction between species $X$ (density $N_{X}$ ) and species $Y$ (density $N_{Y}$ ) by a simple Lotka-Volterra model,

$$
\begin{aligned}
& \frac{d N_{X}}{d t}=\left[-r_{X}(x)-c_{X} N_{X}+y N_{Y}\left(1-\alpha N_{X}\right)\right] N_{X}, \\
& \frac{d N_{Y}}{d t}=\left[-r_{Y}(y)-c_{Y} N_{Y}+x N_{X}\left(1-\beta N_{Y}\right)\right] N_{Y} .
\end{aligned}
$$

The mutualistic traits $x$ and $y$ are measured as per capita rates of commodities traded (a visitation rate by a pollinator, for example); thus, $x N_{X}$ and $y N_{Y}$ represent the probabilities per unit time that a partner individual receives benefit from a mutualistic interaction. Intraspecific competition for commodities provided by the partner species is expressed by the linear density-dependent factors $\left(1-\alpha N_{X}\right)$ and $\left(1-\beta N_{Y}\right)$, as in Wolin (1985). The terms $-c_{X} N_{X}$ and $-c_{Y} N_{Y}$ measure the detrimental effect of intraspecific competition on other resources. The mutualism being obligate, the intrinsic growth rates $-r_{X}(x)$ and $-r_{Y}(y)$ are negative, and $r_{X}(x)$ and $r_{Y}(y)$ increase with $x$ and $y$, respectively, to reflect the costs of mutualism.

Ecological dynamics. A standard analysis of the thus defined ecological model shows that the situation in which both species are extinct, $N_{X}=0$ and $N_{Y}=0$, is always a locally stable equilibrium. Depending on the trait values $x$ and $y$, two inner equilibria may also exist in the positive orthant, one being stable (a node) and the other being unstable (a saddle). The transition between the two cases (zero or two equilibria in the positive orthant) is caused by a saddle-node bifurcation. The corresponding bifurcation curve is the closed, ovoid curve depicted in Figures 16.1 a to $16.1 \mathrm{c}$, which separates a region of trait values that lead to extinction from the domain of traits that correspond to viable ecological equilibria.

A mathematical approximation of mutation-selection processes. By assuming that ecological and evolution processes operate on different time scales and that evolution proceeds through the fixation of rare mutational innovations, the rates of change of traits $x$ and $y$ on the evolutionary time scale are given by (Dieckmann and Law 1996)

$$
\begin{aligned}
& \frac{d x}{d t}=\left.\varepsilon_{X} N_{X}^{*} \frac{\partial f_{x}}{\partial x^{\prime}}\right|_{x^{\prime}=x}, \\
& \frac{d y}{d t}=\left.\varepsilon_{Y} N_{Y}^{*} \frac{\partial f_{y}}{\partial y^{\prime}}\right|_{y^{\prime}=y} .
\end{aligned}
$$

Parameters $\varepsilon_{X}$ and $\varepsilon_{Y}$ denote evolutionary rates that depend on the mutation rate and mutation step variance (see Box 11.3 for further details); $N_{X}^{*}$ and $N_{Y}^{*}$ are the equilibrium population densities of resident phenotypes $x$ and $y$ (these factors occur because the likelihood of a mutation is proportional to the number of reproducing individuals); $f_{X}\left(x^{\prime}, x, y\right)$ and $f_{Y}\left(y^{\prime}, x, y\right)$ are the invasion fitnesses (defined as per capita rates of increase from initial rarity; Metz et al. 1992) of a mutant phenotype $x^{\prime}$ of species $X$ and of a mutant phenotype $y^{\prime}$ of species $Y$ in a resident association $x, y$. continued 


\section{Box 16.2 continued}

Evolutionary dynamics under symmetric versus asymmetric competition. Competition between two individuals is symmetric if the detrimental effect of their competitive interaction is the same on both individuals; otherwise, their competition is asymmetric. With symmetric competition, we have $\partial f_{X}=-r_{X}^{\prime}(x) \partial x$ and $\partial f_{Y}=-r_{Y}^{\prime}(y) \partial y$. Therefore, from any ancestral state, the process of mutation and selection causes the monotonic decrease of the traits $x$ and $y$ toward zero. Thus, all evolutionary trajectories eventually hit the boundary of ecological viability. Asymmetric competition between two phenotypes of species $X$ that provide commodities at different rates is modeled by replacing the constant competition coefficient $\alpha$ with a sigmoid function of the difference in the rate of commodity provision (Matsuda and Abrams 1994c; Law et al. 1997; Kisdi 1999). With such a function, a large positive difference implies that $\alpha$ approaches its minimum value, whereas a large negative difference results in a value of $\alpha$ close to its maximum. The absolute value of the slope of this function at zero difference then provides a measure of the degree of competitive asymmetry. Likewise, we can define an asymmetric competition function $\beta$ for species $Y$. The first-order effect on fitness induced by a small difference $\partial x$ in the rate of commodity provision is then equal to $\partial f_{X}=\left[-r_{X}^{\prime}(x)+\alpha^{\prime} y N_{X}^{*} N_{Y}^{*}\right] \partial x$, where $N_{X}^{*}$ and $N_{Y}^{*}$ are the population equilibria that are solutions of $-r_{X}(x)-c_{X} N_{X}+y N_{Y}\left[1-\alpha(0) N_{X}\right]=0$ and $-r_{Y}(y)-c_{Y} N_{Y}+x N_{X}\left[1-\beta(0) N_{Y}\right]=0$, and $\alpha^{\prime}=\left|\alpha^{\prime}(0)\right|$ is the degree of competitive asymmetry. Likewise, we obtain $\partial f_{Y}=\left[-r_{Y}^{\prime}(y)+\beta^{\prime} x N_{X}^{*} N_{Y}^{*}\right] \partial y$, with $\beta^{\prime}=\left|\beta^{\prime}(0)\right|$. The intersection point of the isoclines $\partial f_{X} / \partial x=0$ and $\partial f_{Y} / \partial y=0$ defines a so-called evolutionary singularity (Geritz et al. 1997; Chapter 11). To investigate the existence and stability of this point, we performed an extensive numerical bifurcation analysis with respect to the degrees of asymmetry $\alpha^{\prime}$ and $\beta^{\prime}$; these parameters have the convenient property that they do not influence the ovoid domain of traits $(x, y)$ that ensure ecological persistence. In general, there is a wing-shaped region of parameters $\alpha^{\prime}$ and $\beta^{\prime}$ in which the evolutionary singularity exists as a stable node within this domain (see gray area in Figure 16.1d). Interestingly, the effect of changing the evolutionary rates $\varepsilon_{X}$ and $\varepsilon_{Y}$ is confined to the "tips" of this wing-shaped region - neither the front edge nor the back edge is affected by these parameters, whereas increasing (decreasing) the ratio $\varepsilon_{X} / \varepsilon_{Y}$ shifts the tips toward the upper left (lower right).

environment, first proposed and analyzed by Ferrière et al. (2002). Details of the model are presented in Box 16.2.

\section{Ecological persistence}

The ecological component of the model extends standard Lotka-Volterra equations for mutualisms. Each mutualistic species is characterized by:

Its intrinsic growth rate;

- The rate at which it provides commodities to partners (e.g., services such as pollination and rewards such as nectar, see Box 16.1); 
- Parameters that measure the strength of intraspecific competition for the commodities that partners provide in return, as well as for other resources.

The direct cost of producing commodities impacts the intrinsic growth rate of each species, an effect modeled by discounting a baseline intrinsic growth rate by a cost function for a specific commodity.

The model predicts that the ecological persistence of a mutualism is determined by three types of factors (Box 16.2):

- Individual life-history traits: the baseline intrinsic growth rates and the shape of the commodity cost functions.

- Interaction traits: the specific rates of commodity provision, and the strength of intraspecific competition for commodities provided by partners and for other resources.

- Species abundance: an Allee effect occurs that results in thresholds on each species' population size below which mutualism cannot persist.

Individual and interaction traits combine in a complex manner to determine the ecological viability of mutualisms and the minimum thresholds that each population size must exceed for the association to persist. Yet, in general, for fixed individual and competition parameters, ecological viability is achieved provided the rates of commodity provision are neither extremely low nor too high. At the boundary of the set of commodity provision rates that permit ecological persistence, the system undergoes a catastrophic bifurcation and collapses abruptly.

\section{Evolutionary persistence}

The model described here (Ferrière et al. 2002) provides a general explanation for the evolutionary origin of cheaters and the unexpected stability of mutualistic associations in which cheating occurs. To identify factors that promote the evolutionary persistence of mutualism, we incorporate an evolutionary dimension within the ecological model by assuming that the partners' rates of commodity provision can be subject to rare mutation. The resultant coevolutionary dynamics follow the selection gradients generated by the underlying ecological dynamics (Box 16.2; Hofbauer and Sigmund 1990; Abrams et al. 1993; Dieckmann and Law 1996; Chapter 11), and can have a dramatic impact on the long-term persistence of the association. If individuals compete with equal success for the commodity provided by the partner species, regardless of how much those competing individuals invest in mutualism (symmetric competition), long-term evolutionary dynamics will always drive the association toward the boundary of the ecologically viable region of the trait space, irrespective of the ancestral state; this results in evolutionary suicide (Chapter 11). The mutualism erodes because cheating mutants that invest less in mutualism are under no competitive disadvantage and thus are always able to invade, which ultimately drives the partner species to extinction. However, as a rule, competition in nature is asymmetric (Brooks and Dodson 1965; Lawton 1981; Karban 1986; Callaway and Walker 1997). Clearly, if any competitive asymmetry within either species gives an advantage to individuals that provide fewer 
(a)
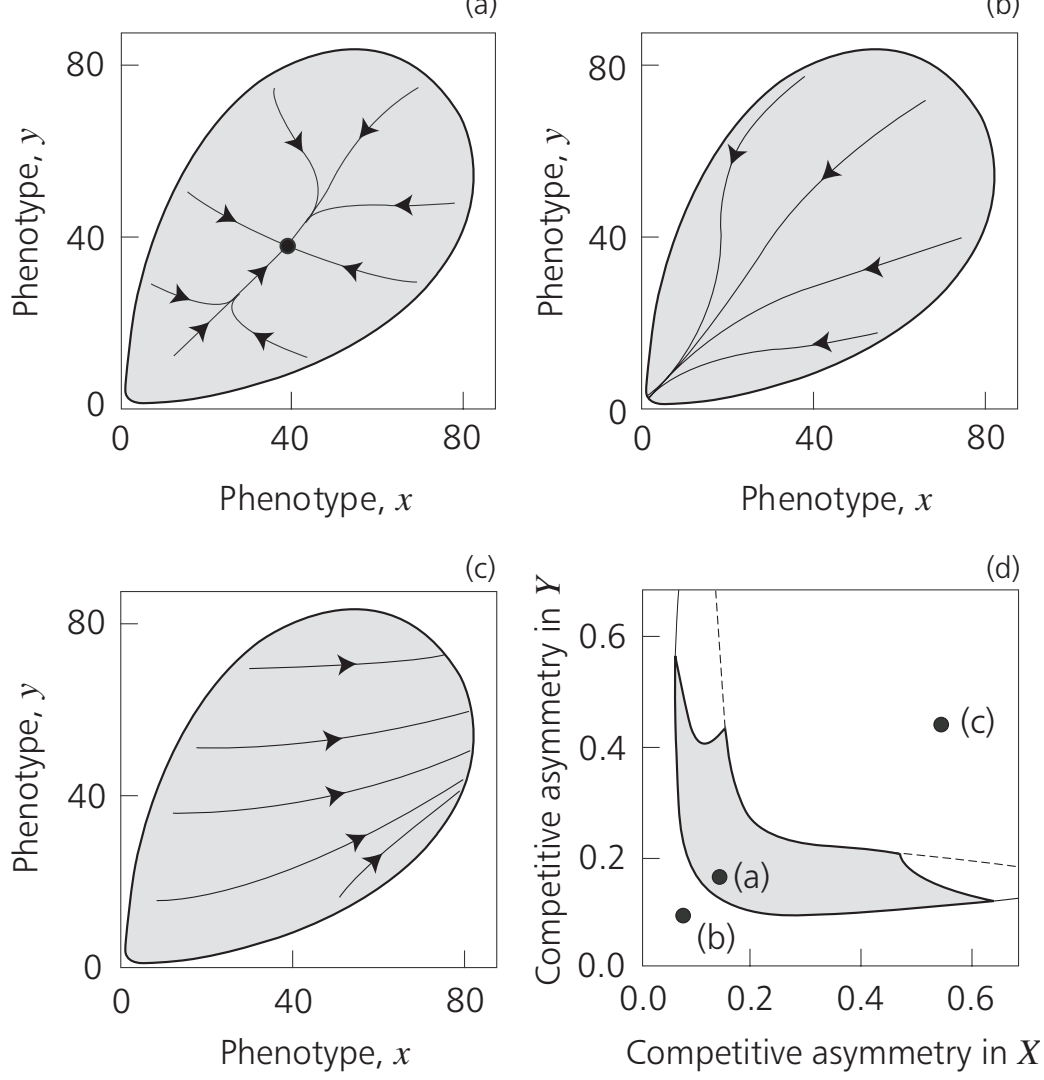

Figure 16.1 Competitive asymmetry and the evolutionary persistence of mutualism. The ovoid domain delineates the adaptive rates $x$ and $y$ of commodity provision by each species that make the mutualistic association ecologically viable. Each oriented curve depicts an evolutionary trajectory that starts from a different ancestral phenotypic state. (a) Convergence toward an evolutionary attractor that is ecologically viable (filled circle). Specific degrees of competitive asymmetry are $\alpha^{\prime}=0.035$ and $\beta^{\prime}=0.035$. (b) Evolutionary suicide through selection of ever-reduced mutualistic investments $\left(\alpha^{\prime}=0.01\right.$ and $\left.\beta^{\prime}=0.01\right)$. (c) Evolutionary suicide by runaway selection for ever-increased mutualistic investments $\left(\alpha^{\prime}=0.20\right.$ and $\beta^{\prime}=0.40$ ). (d) Dependence of the adaptive dynamics regime on the degrees of competitive asymmetry in species $X$ and $Y$, as measured, respectively, by $\sqrt{\alpha^{\prime}}$ (horizontal axis) and $\sqrt{\beta^{\prime}}$ (vertical axis). The gray area shows the convergence to an evolutionary attractor that is ecologically viable; the blank area shows evolutionary suicide. The curves (continuous and dashed) that delineate the wing-shaped gray area are bifurcation curves obtained from the numerical analysis of Equations (c) and (d) in Box 16.2 (see Ferrière et al. 2002 for further details). Points (a), (b), and (c) correspond to the panels (a), (b), and (c). Parameters: $r_{X}(x)=0.01\left(x+x^{2}\right), r_{Y}(y)=0.01\left(y+y^{2}\right), c_{X}=1, c_{Y}=2$. Source: Ferrière et al. (2002).

commodities, the evolutionary suicide described above would be unavoidable. By contrast, individuals often discriminate among partners according to the quantity of rewards they provide, and associate differentially with higher-reward producers (e.g., Bull and Rice 1991; Christensen et al. 1991; Mitchell 1994; Anstett et al. 1998). Such a competitive premium, in effect, generates a selective force that can counter the pressure to reduce the provision of commodities. 
Three outcomes are then possible (Figure 16.1d), depending on the strength of the asymmetry:

- At intermediate degrees of competitive asymmetry, the mutualistic association evolves toward an ecologically viable evolutionary attractor (Figure 16.1a). Two things can happen at this point: either selection stabilizes the mutualism or it turns disruptive. In either case, the association persists in the long term.

- If the asymmetry is too weak in either species, a selective pressure that favors a lower provision of commodities predominates in that population. As the total amount of commodities offered to the partner species decreases, the selective pressure induced by competitive asymmetry in the partner weakens, and selection to reduce the provision of commodities takes over on that side of the interaction also. Extinction is the inexorable outcome (Figure 16.1b).

- If the asymmetry is too strong on either side, the selective pressure that favors the provision of more commodities predominates, which causes runaway selection until the costs incurred are so large that the association becomes non-viable. Again, extinction is the outcome (Figure 16.1c).

Thus, ecological stability alone cannot provide a sufficient condition for the evolutionary persistence of a mutualism subject to natural selection. According to the analysis above, evolutionary suicide is expected to be a general property of mutualisms that involve too little or too much asymmetry in intraspecific competition for commodities provided by partners.

\subsection{Anthropogenic Threats to Mutualisms}

The ability of mutualisms to persist both on a short-term ecological time scale and on a longer-term evolutionary time scale, therefore, is closely related to the partners' life histories, behaviors, and abundances. Hence, any form of anthropogenic change that impacts these variables will threaten mutualisms. Below we address the known effects on mutualisms of two of the most serious anthropogenic threats, habitat fragmentation and biological invasions.

\section{Habitat fragmentation}

One of the more striking effects of human land use, and one that has increased dramatically in recent decades, is habitat fragmentation. Fragmentation, a phenomenon treated in depth in Part D, creates small populations from large ones by weakening or severing their linkage through dispersal. At the species level, problems caused by habitat fragmentation include increases in genetic drift, inbreeding depression, and demographic stochasticity (Chapter 4). As discussed in Chapter 14, diverse adaptive responses to fragmentation can be expected. Habitat fragmentation is of major concern beyond the species level also, since organisms can experience the effects of fragmentation indirectly, via its effects on the species with which they interact either positively or negatively.

Habitat fragmentation can impact all the factors that promote the ecological and evolutionary persistence of mutualisms. Reductions in the population size of 
one species caused by fragmentation can lead to failure of their mutualists as well, with a resultant local ecological instability. Aizen and Feinsinger (1994), for example, documented that the loss of native bee pollinators from forest fragments in Argentina reduced the seed production of about $75 \%$ of plant species within those fragments; reproduction of some species ceased almost entirely. Habitat loss and edge effects may reduce habitat quality for mutualists, and thus mutualist population sizes as well (Jules and Rathcke 1999). Intrinsic life-history traits and behaviors of mutualists may also be disrupted by fragmentation. For instance, habitat patches may become so isolated that mobile species become unable or unwilling to travel between them (Goverde et al. 2002); this affects the degree to which they provide mutualistic services and potentially alters the mode and intensity of intraspecific competition for these services. Ultimately, persistent isolation of local populations caused by fragmentation may lead to evolutionary changes in life-history traits linked to mutualism (e.g., Washitani 1996), although many other outcomes are also possible (see Sections 16.4 and 16.5).

\section{Biological invasions}

If the loss of partners can raise a major ecological threat to mutualisms, the reverse phenomenon - the addition of new species - can be at least equally problematic. A useful rule of thumb is that roughly $10 \%$ of the introduced species become established and $10 \%$ of these become troublesome pests (Williamson and Brown 1986), commonly in the context of interspecific interactions in their new habitat.

Biological invasions pose a number of threats to mutualisms. Predatory, parasitic, and pathogenic invaders can greatly reduce native populations or alter their life-histories and behaviors, with strong ecological impacts on the mutualists of those natives. For example, the Argentine ant, a particularly successful invader worldwide, can decimate populations of ground-dwelling insects (Holway 1998). In Hawaii, these ants substantially reduce insectpollinator abundance, with potentially disastrous consequences for the persistence of native plants (Cole et al. 1992). Invaders can sometimes outcompete and displace native mutualists, generally

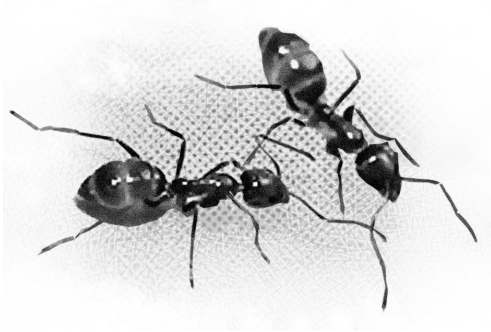

Argentine ant Linepithema humile to the detriment of their partner. Bond and Slingsby (1984) documented how the Argentine ant replaced native ant species as the seed disperser of South African Proteaceae, which has led to a reduced seedling establishment. Its preference for seeds that bear relatively small food bodies (elaiosomes) has resulted in a shift in local plant communities toward dominance by species with seeds that contain the preferred rewards (Christian 2001). Perhaps the most important case of mutualist replacement is the honeybee, intentionally transported by humans worldwide, but often a rather poor pollinator compared to the native insects they displace competitively (Buchmann and Nabhan 1996; Kearns et al. 1998). Invaders may ultimately induce evolutionary modifications in interactions within and between 
species. Such effects have not yet been demonstrated for mutualisms, although they are well-documented for certain other kinds of interaction (e.g., Singer et al. 1993).

Not all introduced species have negative impacts, however. Certain invaders join native mutualist assemblages with no measurable negative effects on the residents, and probably some positive effects (Richardson et al. 2000). Furthermore, invaders can fill the gap created when

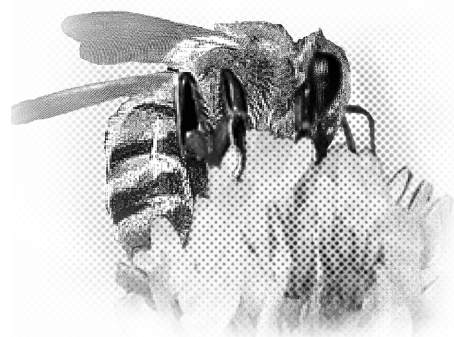

Honeybee Apis mellifera a native mutualist has been driven to extinction, saving its partner from a similar fate. For example, an introduced opossum is now an effective pollinator of Freycinetia baueriana, a New Zealand liana that has lost its bat pollinator (Lord 1991). In the same vein, Janzen and Martin (1982) argued convincingly that numerous tree and shrub species in Central America still exhibit traits for seed dispersal by gomphotheres, large herbivorous mammals extirpated about 10000 years ago, quite possibly through overhunting by humans (Martin and Klein 1984). Yet many of these plants thrive today, dispersed effectively by introduced livestock not too different ecologically from their extinct, coevolved dispersers.

\section{Other anthropogenic threats}

Other anthropogenic threats to mutualism are well known, but have been investigated less, so that their impact on factors that promote the ecological and evolutionary persistence of these interactions remains unclear. For example, agriculture clearly poses numerous problems for native plant-pollinator interactions. One problem of particular evolutionary interest is introgression from genetically engineered crop plants into related wild species (Snow and Palma 1997), which can alter the floral traits that attract pollinators (Lee and Stone 1998). Pollutants impact many mutualisms: the effects of automobile exhaust on lichen symbioses (Lawrey and Hale 1979), agrochemicals on pollinators (Buchmann and Nabhan 1996), and acid rain on endophytic fungi (Helander et al. 1996; Lappalainen et al. 1999) are particularly well documented. Finally, it has been recognized increasingly that global change impacts diverse species interactions (Kareiva et al. 1993). For example, elevated levels of $\mathrm{CO}_{2}$ have both direct and indirect effects on mutualisms between plants and their root symbionts (Thomas et al. 1991; Diaz 1996; Staddon and Fitter 1998).

\section{Which mutualisms are most at risk?}

A major goal of conservation biology is to turn isolated case histories, like those summarized above, into testable predictions as to which species can be expected to be most vulnerable to anthropogenic change. One prediction has been cited repeatedly: organisms that are obligately dependent on a single species have the most to lose from the disruption of that mutualism. In contrast, organisms dependent on a 
broader array of species, or that succeed to some extent without mutualists at all, are believed to be somewhat buffered from the effects of such disruption. In the following two sections we consider first how specialized mutualisms, and then how more generalized mutualisms, are expected to respond to anthropogenic change.

\subsection{Responses of Specialized Mutualisms to Threats}

To summarize so far, we have seen that any force of anthropogenic change that drives down the numbers of one species can reduce indirectly the success of organisms dependent upon that species. What are the likely consequences for species with narrow or strict dependences on threatened species? (A classic example of a species-specific, obligate mutualism commonly thought to be at great risk from anthropogenic change is the interaction between fig trees and their fig-wasp pollinators, described in Box 16.3.) We consider three scenarios here:

- An ecological vortex in which both species dwindle to extinction;

- Ecological resiliency that buffers organisms from a fate similar to their mutualists;

- Evolutionary responses that rescue organisms from their mutualists' fate.

\section{Rarity of coextinction?}

We have already cited several examples in which anthropogenic impacts to one species have reduced indirectly the success of its mutualists. Interestingly, however, there is no documented case in which such joint failure has led to a linked extinction, at either the local or global scale. The case of the dodo and the tambalacoque tree is often cited in this context, but mistakenly. The dodo, a bird endemic to Mauritius, was hunted to extinction in the 1700s; this has supposedly driven to near extinction an endemic tree with seeds that could be dispersed by the dodo only (Temple 1977). However, more recent investigations show that over the past 300 years new individuals have been recruited into the tree population, which implicates another disperser or dispersers. Furthermore, morphological evidence suggests that the dodo was probably more of a seed predator than a mutualistic seed disperser (Witmer and Cheke 1991).

What explains the apparent rarity of coextinc-

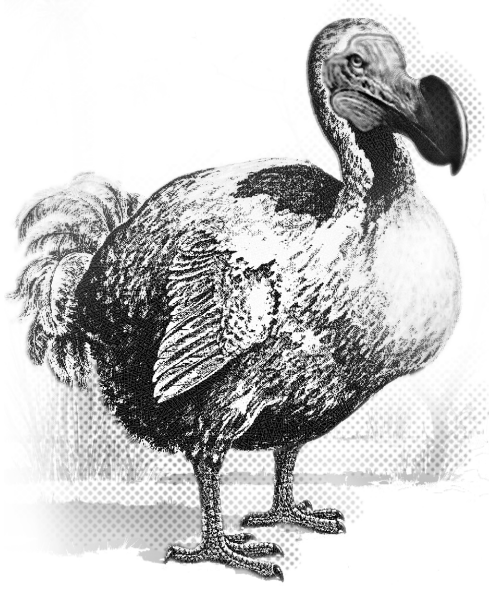

Mauritian dodo Raphus cucullatus tion? We can offer three possibilities. First, it is perhaps only very recently that ecological conditions conducive to this phenomenon have appeared. This seems highly unlikely. Although the current biodiversity crisis is apparently generating a higher extinction rate than any previous mass extinction event (Wilson 1992), probably $99 \%$ of all species that have ever existed on Earth are now extinct, which 
Box 16.3 Is the fig-pollinator interaction a threatened mutualism?

The mutualism between fig trees (about 750 Ficus species) and their pollinator wasps (family Agaonidae) has long served as a model for the intricate adaptations and extreme specialization that coevolution can produce. Most fig species are pollinated exclusively by a single species of fig wasp, which in turn is associated with a single fig species. The female wasps pollinate fig inflorescences, then deposit their eggs in certain flowers. Their offspring feed on the developing seeds. When the wasps are mature, they mate; the females collect pollen and then depart in search of an oviposition site. Trees within a fig population generally flower in tight withintree synchrony, but out of synchrony with each other, which forces the wasps to depart their natal tree. Hence, figs sacrifice some proportion of their seeds to guarantee that their pollen will be dispersed effectively among individuals (Bronstein 1992; Anstett et al. 1997a; Weiblen 2002).

Figs are thought to be of exceptional conservation significance, yet subject to exceptional threats from anthropogenic change (McKey 1989; but see Compton and McCormack 1999). Their significance is linked to their unusual phenology. Since trees flower out of synchrony with each other, they also fruit out of synchrony; this provides one of the only year-round food sources for vertebrates in tropical habitats (Shanahan et al. 2001a). Their vulnerability, however, is an outcome of this same phenology. Fig wasps are tiny and fragile, and live a day or two at most as adults. During this brief period, they must transit large distances in search of their single mutualist species. Simulation models indicate that fairly high numbers of trees must be present within their flight range to give them any chance of locating a flowering individual (Bronstein et al. 1990; Anstett et al. 1995, 1997b). Habitat alterations that reduce their chances further - removal of fig trees, fragmentation of their habitats, pesticide spraying, etc. - are likely to lower the success of fig fruiting, with potentially disastrous consequences for vertebrate populations.

However, a number of very recent discoveries about this mutualism suggest that it exhibits more resilience than once thought:

First, its level of specificity is lower than commonly believed: some figs have different pollinator species in different parts of their range, or even multiple pollinators at a single site (Rasplus 1996).

- Second, figs have remarkable adaptations to attract pollinators from long distances (Gibernau and Hossaert-McKey 1998), as well as adaptations that allow the inflorescences to persist for weeks while waiting for pollinators to arrive Khadari et al. 1995).

- Finally, fig wasps regularly travel far longer distances than they were once given credit for (Nason et al. 1998).

These traits help account for situations in which fig-pollinator mutualisms have been re-established rapidly after major disruptions (Bronstein and Hossaert-McKey 1995; but see Harrison 2000). They may also explain why, although species-specific pollination is certainly an important limit to range extension [since figs cannot occur where their pollinator is unable to persist or disperse (Kjellberg and Valdeyron 1990)], figs can also be surprisingly effective colonizing species (Shanahan et al. 2001b), as well as aggressive invaders in some habitats (McKey 1989). 
indicates that the risk of coextinction is certainly not a new problem. It may well be a growing problem, however.

Second, and much more likely, an absence of evidence may not be evidence of absence: coextinction may actually occur, but be extremely difficult to detect. To determine the underlying cause of any extinction is problematic, in part because, as discussed in Part A of this book, many factors interact to doom populations once they are critically small. Also, the ability of paleontological data to reveal linked extinctions is limited: the fossil record rarely offers evidence as to why a given species has disappeared, and its temporal resolution is nearly always too crude to test an ecological hypothesis such as this. Our best hope to document coextinction may be to observe it in the field while it is happening, although if we see it, it is likely that we would attempt to prevent it.

The final possibility as to why coextinctions have not been documented is that mutualisms might be more resilient to change than we have given them credit for. The evolutionary past may have endowed mutualisms with some capacity to respond, ecologically or evolutionary, to current and future challenges - even in situations that, logically, we might expect would doom them. We wish to stress that we do not intend to trivialize the risk of coextinction. However, by investigating the kinds of mutualisms that seem to have evolved some ecological or adaptive resilience against coextinction, we can better focus our most intensive conservation efforts on those that do not.

\section{Past adaptations that promote ecological resiliency}

Generalization (Section 16.5) is often considered as a characteristic that buffers mutualisms from anthropogenic change. When specialized mutualisms are examined closely, however, it is discovered that they, too, exhibit adaptations that confer some resiliency. (Some of these are summarized in Box 16.3, for the fig pollination mutualism.) The explanation for the existence of these traits seems fairly straightforward: even in the absence of anthropogenic change, most natural environments are extremely variable. Surely, the only highly specialized and/or obligate mutualisms that have been able to persist to the present day are those able to persist in the face of variability. Below we consider three kinds of adaptations that help specialists survive in fluctuating environments: an ability to wait, an ability to move, and an ability to generalize. [See Bond (1995) for an expanded discussion of these and other such traits.] We then consider the degree to which these traits can rescue species from anthropogenic change.

We can find no examples of mutualism in which each of the two species has a single opportunity in its life to attract the single partner upon which it depends. In the face of anything other than an extremely constant environment and high population sizes of mutualists, such a relationship seems doomed to failure. Rather, at least one of the two species has the opportunity to acquire mutualists either continuously or at repeated intervals. In either case, that organism possesses some ability to persist for a while without mutualists (although it possibly experiences 
reduced success while it waits). For instance, certain flowers can persist in a receptive state for days or weeks until pollinators arrive (Primack 1985; Khadari et al. 1995), and orchid seeds do not germinate until they are invaded by their obligate beneficial mycorrhizae (Dressler 1981). Finally, many organisms can experience at least minimal success even when mutualists are entirely absent. That is, their mutualisms may be specialized, but they are not obligate. For example, plants may reproduce largely by self-pollination during intervals when pollinators are absent, though the offspring that result are likely to be genetically inferior to those produced in the presence of mutualist pollinators.

Organisms that can wait for mutualists are, as a rule, relatively immobile. Mobile species exhibit other suites of traits that increase the success of their mutualisms. Certain organisms, both terrestrial and aquatic, show remarkable abilities to track species-specific volatile substances released by physically distant, immobile mutualists (Ware et al. 1993; Brooks and Rittschof 1995; Elliott et al. 1995; Takabayashi and Dicke 1996). Larger and more cognitively advanced species learn where mutualists are likely to be found, and can shift to new areas when this distribution changes (Bronstein 1995).

Finally, specialists often have greater potential to associate successfully with the "wrong" mutualist than we usually realize, because the switch only occurs

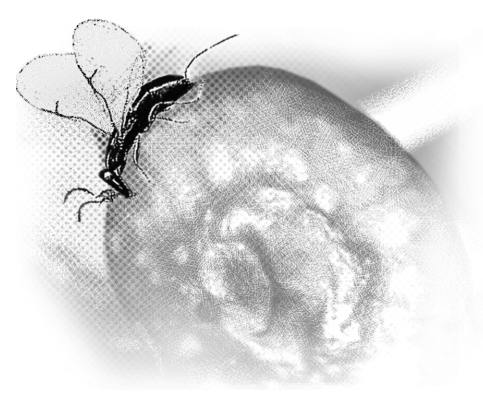

Fig wasp (on fig)

Courtella wardi (or is only obvious) when the "right" mutualist is rare or absent. For example, many bees, termed oligolectic species, visit only one or a very few plant species for pollen. When flowering of the usual host fails, many of these bees can shift successfully to plant species with which they are almost never associated under normal conditions (Wcislo and Cane 1996). At a very low, but detectable, frequency native fig wasps visit fig species that have been introduced without their own pollinators (McKey 1989; Nadel et al. 1992); if the native and exotic figs are related closely enough, both partners within the mismatched relationship are able to reproduce, although generally at reduced rates (HossaertMcKey, unpublished data).

What is the significance of these adaptations for life in environments that vary naturally, in a conservation context? They allow organisms with specialized mutualisms to cope with anthropogenic change at the mesoscale (i.e., change that is relatively local and relatively short in duration). They eliminate the risk of failing catastrophically in response to a brief absence of partners, and they permit populations to persist for some time when mutualists are in decline. On the other hand, this situation cannot necessarily continue for protracted periods. Fitness is likely to decline eventually and, with it, population sizes; as populations decline, inbreeding and other detrimental genetic effects follow. Ultimately, the degree of resiliency offered by these traits depends on: 
- The nature and spatiotemporal scales of human disturbance, particularly with reference to the nature and scales of variation that the species of interest has experienced historically.

The species' ability to evolve further in response to environmental change.

\section{Evolutionary responses}

There is abundant evidence that anthropogenic change initiates evolutionary responses within species involved in antagonistic interactions. For example, native animals can evolve to feed efficiently on novel food items (Singer et al. 1993) and to resist novel pathogens (Dwyer et al. 1990). Phenomena like these have barely been investigated in mutualistic interactions, although it seems probable that they exist. In the only such study that we know, Smith et al. (1995) demonstrated that a Hawaiian honeycreeper (whose coevolved nectar plant was driven to extinction) has evolved a bill shape within the past 100 years that allows it to feed from a more common native species.

The model introduced in Section 16.2 yields some insights into the ecological and evolutionary dynamics of specialized mutualisms in a slowly changing envi-

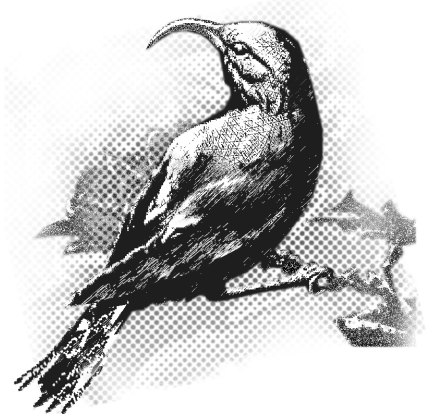

Hawaiian honeycreeper (Iiwi)

Vestiaria coccinea ronment. Although a comprehensive analysis lies beyond the scope of this chapter, a graphic interpretation of Figure 16.1d suffices to illustrate the potentially dramatic consequences on the viability of a mutualism's evolutionary response to environmental change. Environmental change that affects the degree of competitive asymmetry in one or the other species is likely to lead to "evolutionary trapping" (Chapters 1 and 11): as the coefficient of asymmetry in one species slowly decreases or increases, the association tracks an evolutionary attractor that eventually becomes unviable. This can be seen in Figure 16.1d: given that the asymmetry coefficient is fixed for one species, there is a bounded range of asymmetry coefficients for its mutualist species that permits evolutionary stabilization at an ecologically viable equilibrium. When environmental change causes this parameter to hit the limits of its range, coextinction occurs through rapid evolutionary suicide of the kind depicted in Figure 16.1c (when the asymmetry coefficient hits the upper threshold), or in Figure 16.1b (when the asymmetry coefficient reaches the lower threshold). Interestingly, the range of asymmetry coefficients that one population may span without compromising the evolutionary persistence of the whole association is larger if the degree of competitive asymmetry and/or the level of genetic variability in the partner species is low.

At present, empirical data that would allow direct assessments of whether potentially disastrous evolutionary trajectories are occurring or will occur are lacking. However, we can offer one suggestion of a likely situation in which such a development may have already started. It has recently been shown that elevated $\mathrm{CO}_{2}$ levels and global warming can alter flowering phenology and flower nectar 
volumes in certain plant species (Erhardt and Rusterholz 1997; Ahas et al. 2002; Fitter and Fitter 2002; Inouye et al. 2002; Dunne et al. 2003). Phenologies of different species appear to be shifting to different degrees, and in different directions: for example, Fitter and Fitter (2002) report that while 16\% of British flowering plants are flowering significantly earlier than in previous decades (with an average advancement of 15 days in a decade), another $3 \%$ of species are flowering significantly later than they once did. This is likely to result in novel groups of plant

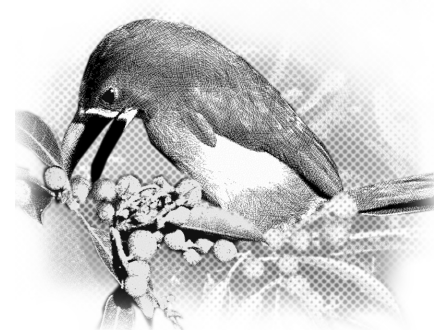

Emerald toucanet Aulacorhynchus prasinus species blooming simultaneously, between which individual pollinator species are becoming able to choose for the first time. Plants that are currently highly preferred and relatively specialized nectar resources may progressively become disfavored by their pollinators, as more rewarding plant species previously matched with other pollinators come into competition for the first time. Conversely, previously disfavored plants may slowly gain competitive advantage among newly coflowering species that are even less rewarding. It would thus seem wise to initiate studies of changing mutualisms within changing communities now, so as to be able to predict and possibly prevent incipiently suicidal evolutionary trajectories.

\subsection{Responses of Generalized Mutualisms to Threats}

In generalized mutualisms, species gain benefits from multiple partner species rather than a single one. For example, in contrast to the obligate species-specific mutualism between figs and fig wasps (Box 16.3), figs are involved in facultative and highly generalized mutualisms with the birds and mammals that disperse their seeds. There are at least three ways in which generalization can buffer mutualisms from a changing environment:

- Rarity or extinction of one species is unlikely to drive the reproductive success of its mutualist to zero, because other beneficial partners are still present. Even in relatively undisturbed habitats, one commonly sees great year-to-year and site-to-site variation in the diversity of mutualist assemblages (e.g., Horvitz and Schemske 1990; Jordano 1994; Alonso 1998); quite commonly the success of individual species that benefit from these assemblages does not track that variation closely.

- Loss of one partner can spur increases in the abundance of alternative partners that might previously have been excluded or suppressed competitively; these alternative partners can be equally effective, or even more effective, mutualists (e.g., Young et al. 1997).

- Finally, the fairly generalized traits involved in the attraction and reward of diverse mutualists can function to attract and reward partners that may have no common evolutionary history with that species. One such adaptation is the elaiosome, a small lipid-rich body attached to certain seeds, which has evolved multiple times and which appeals to diverse seed-dispersing ants worldwide 
(Beattie 1985). Invasive plants with elaiosomes are commonly dispersed by native ants (Pemberton and Irving 1990), while native plants with elaiosomes can be dispersed (although often comparatively poorly) by invasive ants (Bond and Slingsby 1984; Christian 2001).

Despite such buffering, there is no doubt that in recent years generalized mutualisms have suffered major impacts from anthropogenic change. Three examples of the disruption of generalized plant-pollinator mutualisms should suffice to make this point:

- Aerial spraying of herbicides in Eastern Canada during the 1970s catastrophically decreased populations of generalist bee pollinators. Subsequent reproductive failures in both native and crop plants have been well documented (Thomson et al. 1985).

- Shrinking and increasingly isolated plant populations may fail to attract pollinators, which leads to Allee effects that draw populations downward toward extinction (Groom 1998; Hackney and McGraw 2001).

- Invasive plants can outcompete native species for pollination services, which results in the local decline of native populations. For example, purple loosestrife, a weed introduced to North America, has been reducing both the pollinator visitation and subsequent seed set of a native congener (Brown et al. 2002).

What kinds of evolutionary dynamics in response to anthropogenic change can be expected in generalized mutualisms like these? To address this question, it becomes clear that one must adopt a perspective that goes beyond the purely pairwise approach that has characterized most theoretical work on mutualism (Stanton 2003). Here we introduce a simple adaptive dynamics model to illustrate the disturbing potential for evolutionary ripple effects to cascade through more complex ecological communities. More generally, we can look upon this model as a contribution toward elucidating the importance of community context when addressing questions in evolutionary conservation biology (Chapter 17).

\section{Flexible mutualistic coadaptation}

We focus on an ecological community that comprises two pairs of mutualistic species. This setup is chosen because switches between alternative mutualistic partners are important (as highlighted in Section 16.3), and also in an effort to keep matters tractable. In Figure 16.2 species 1 and 2, as well as species 3 and 4 , are coupled through mutualistic interactions. In addition, species 2 and 3 can also engage in mutualism, as can species 1 and 4; thus, all four species potentially are generalists, within the bounds of this simple community structure. We can think, for example, of species 1 and 3 as two plants and of species 2 and 4 as two pollinators: species 2 can then pollinate both plants, and species 3 can be pollinated by both pollinators. The alternative couplings (i.e., 2 with 3 , and 1 with 4) are, however, less efficient than the primary couplings (i.e., 1 with 2 , and 3 with 4) in enabling the mutualistic exchange of commodities such as pollen and pollination. Intraspecific competition is present in all four species, and we also 


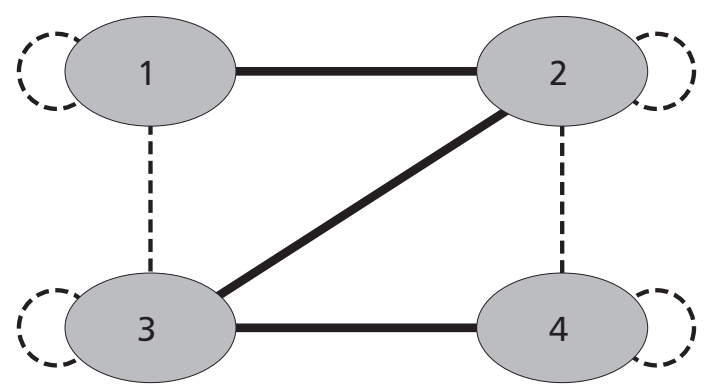

Figure 16.2 A pairwise mutualistic community. The strengths of mutualistic interactions (continuous lines) between four species depend on their level of coadaptation. Dashed lines depict competitive interactions. In this model, the mutualistic interactions can evolve, such that species 2 and 3 can gradually switch between their primary (species 1 and 4 , respectively) and secondary mutualistic partners (species 3 and 2, respectively).

consider interspecific interactions between species 1 and 3 on the one hand, and between species 2 and 4 on the other. Representing this basic setup in terms of Lotka-Volterra systems leads to the model described in Box 16.4.

\section{Coevolutionary responses to environmental disturbances}

We can now utilize this four-species model to explore the evolutionary and coevolutionary implications of changing environmental conditions. We start from a situation in which all the species are adapted so as to be maximally efficient in exchanging commodities with their primary partners, and thus much less efficient when associated with their alternative partners. We then change a single parameter of the model, equivalent to reducing the carrying capacity of species 1 by a factor of 10. This effectively models a situation in which anthropogenic change has altered species 1 's environment in a way that makes it less suitable for these organisms. In response, we can observe one of the following three dynamical patterns of community reorganization (Figure 16.3):

- Primary reorientation and primary extinction. The reduction in species 1's carrying capacity makes it a much less attractive mutualistic partner for Species 2, so species 2 adapts to maximize its coupling with its alternative partner, species 3. We refer to this initial evolutionary response to the imposed environmental change as primary reorientation, and use analogous terms to refer to the subsequent events. Now that the benefit of mutualism received by species 1 from species 2 has been withdrawn, species 1 becomes extinct (Figure 16.3a). Notice that this extinction is not a direct consequence of the imposed environmental change, but, instead, is caused by the evolutionary dynamics that are triggered by the imposed environmental change.

- Primary reorientation, primary extinction, and secondary reorientation. After the imposed environmental change has reduced the abundance of species 1 , species 2 specializes on species 3 . Further evolutionary change may then ensue. In particular, because of its reorientation, species 2 becomes a more attractive partner for species 3, which may induce species 3 to switch from specializing on species 4 to specializing on species 2 (Figure 16.3b). This causes the newly 
Box 16.4 Modeling eco-evolutionary responses of generalized mutualisms to threats A simple adaptive dynamics model for an ecological community that comprises two pairs of mutualistic species (Figure 16.2) can be constructed as follows. Using a basic Lotka-Volterra model architecture (Box 16.2), the per capita growth rates in species $i=1, \ldots, 4$ are given by $r_{i}+\sum_{j} a_{i j} N_{j}$ with intrinsic growth rates $r_{i}$ and population densities $N_{i}$. The symmetric community matrix $a$ contains elements $a_{11}=-c_{11}, \ldots, a_{44}=-c_{44}$, which describe intraspecific competition, and elements $a_{13}=a_{31}=-c_{13}, a_{24}=a_{42}=-c_{24}$, which describe interspecific competition. We assume that species 1 and 4 do not interact, $a_{24}=a_{42}=0$. The remaining six elements of $a$ describe mutualistic interactions and are determined as follows.

Each species possesses an adaptive trait $x_{i}$, bounded between 0 and 1, that describes its degree of adaptation to its primary partner (i.e., of species 1 to species 2 , of species 2 to species 1 , of species 3 to species 4 , and of species 4 to species 3 ), while $1-x_{i}$ describes the degree by which species $i$ is adapted to its secondary partner (i.e., of species 2 to species 3 and vice versa; species 1 and 4 have no secondary partner). In the case of plant-pollinator interactions, the adaptive traits could represent morphological or phenological characters. The strength of mutualistic interactions is $a_{i j}=c_{i j} m_{i j}$, where $j$ is either the primary or secondary partner of species $i$ and $c_{i j}=c_{j i}$ scales the strength of their interaction. We assume that the level of coadaptation, which describes how well the relevant adaptations in species $i$ and $j$ match, is given by $m_{i j}=e_{i j} x_{i j} x_{j i}+\left(1-e_{i j}\right)\left[1-\left(1-x_{i j}\right)\left(1-x_{j i}\right)\right]$. Here, $x_{i j}$ is the degree of adaptation of species $i$ to species $j$, which equals $x_{i}$ if $j$ is the primary and $1-x_{i}$ if $j$ is the secondary partner. The parameters $e_{i j}=e_{j i}$ measure how essential mutual adaptation is to the strength of the mutualistic interaction. When $e_{i j}$ is high, the first term in $m_{i j}$ dominates, such that both $x_{i j}$ and $x_{j i}$ have to be high for the interaction to be strong. By contrast, when $e_{i j}$ is low, the second term in $m_{i j}$ allows the interaction to be strong if only one species is adapted to the partner, regardless of how well the partner itself is adapted. Variations in the resultant levels of matching are illustrated in the figure below.

(a)

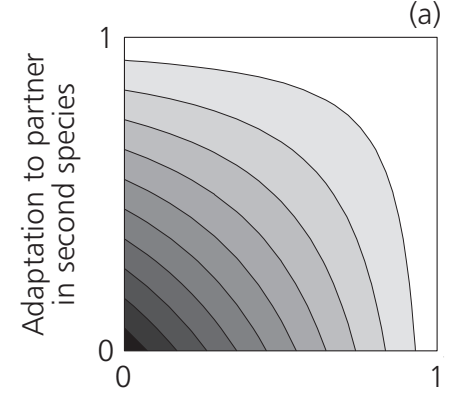

(b)

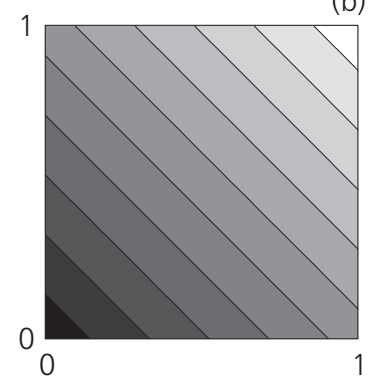

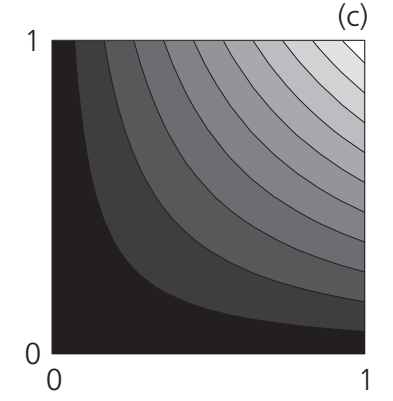

Adaptation to partner in first species

A high level of matching may already be present if just one partner is sufficiently adapted, panel (a), or it may more strictly require both partners to adapt to one another, panel (c). Such a continuum is described by the model parameters $0 \leq e_{i j} \leq 1$; the three cases shown correspond to $e_{i j}=0$ (a), $e_{i j}=0.5$ (b), and $e_{i j}=1$ (c). High levels of coadaptation are indicated in white, and low levels in black. 

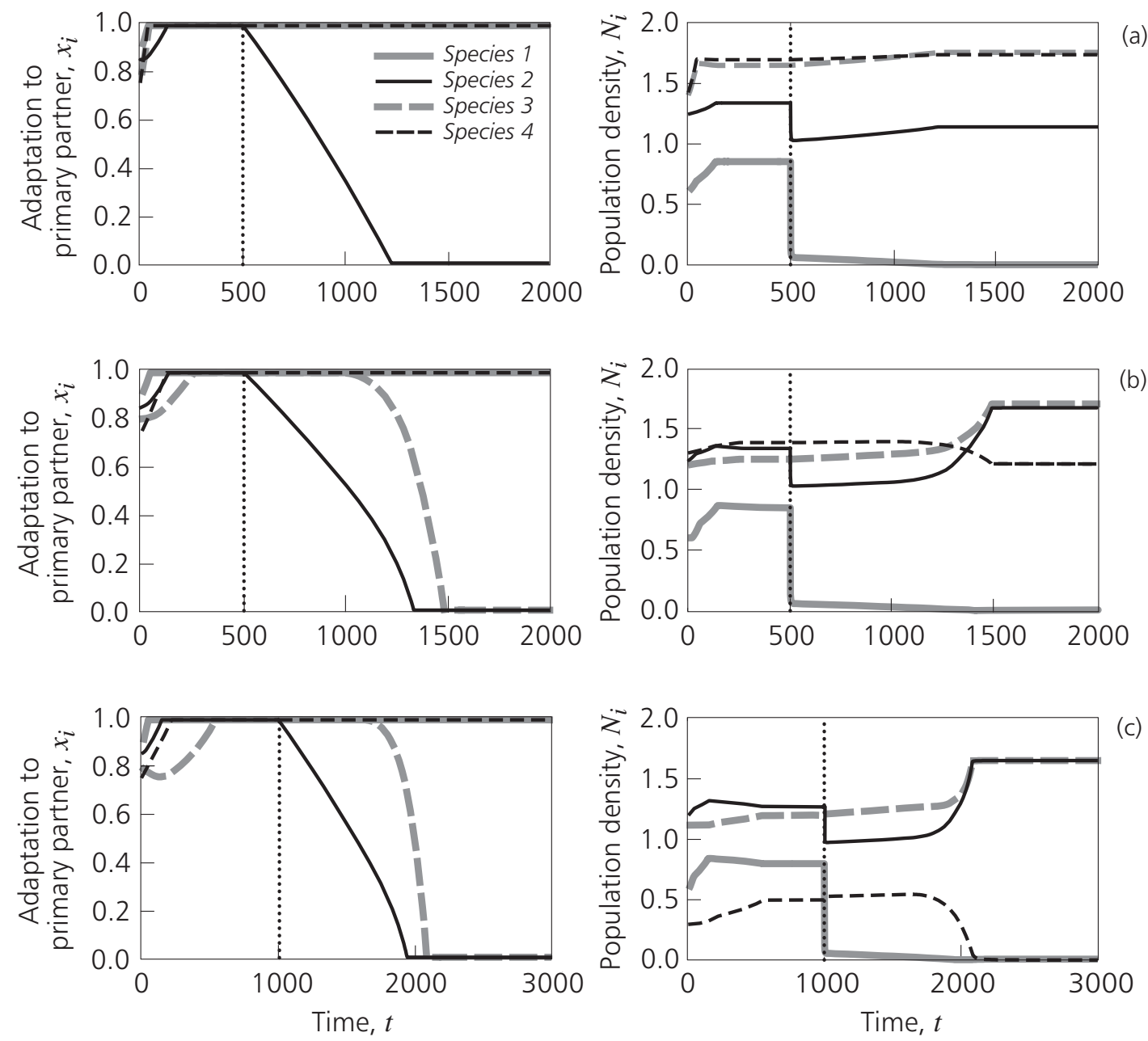

Figure 16.3 Coevolutionary ripple effects of environmental disturbances. The panels show how adaptive trait values (left column) and population densities (right column) change over evolutionary time. At the moments in time indicated by the dotted lines, an abrupt environmental change reduces the carrying capacity of species 1 by a factor of 10 . Before that, selection favors full adaptation of all species to their primary mutualistic partners, whereas after the disturbance alternative coevolutionary responses can unfold. (a) Reorientation of species 2 to species 3 with the resultant extinction of Species 1. (b) The reorientation of species 2 and extinction of species 1 triggers reorientation of species 3 to species 2 . (c) The reorientation of species 2 , extinction of species 1 , and reorientation of species 3 eventually lead to the extinction of species 4. Parameters: (a) $r_{1}=-0.1, r_{2}=r_{3}=r_{4}=1, c_{11}=0.5$ changing to $c_{11}=5, c_{22}=c_{33}=c_{44}=1, c_{13}=c_{24}=0, c_{12}=c_{23}=c_{34}=0.4$, $e_{12}=e_{23}=e_{34}=0.8$; (b) same as (a), except for $c_{34}=0.2$; (c) same as (a), except for $g_{4}=0.15$ and $c_{24}=0.1$. All evolutionary trajectories are based on the canonical equation of adaptive dynamics (Dieckmann and Law 1996).

formed alliance between species 2 and 3 to thrive, and allows it to dominate the community.

- Primary reorientation, primary extinction, secondary reorientation, and secondary extinction. The ripple effects of the initial environmental change may propagate even further through the community. After species 2 and 3 have 
maximized their level of coadaptation, species 4, now that it has essentially lost its mutualistic partner species 3 to species 2, may perish (Figure 16.3c). This illustrates how environmental change that directly affects only one species can cascade relatively easily through a community and induce ecological and evolutionary change in species that are several interaction tiers away from the original perturbation.

Much remains to be studied before we will truly understand the likelihood and implications of coevolutionary cascades in threatened ecological communities. Yet the simple model considered here already cautions against ignoring the potentially wide-ranging consequences of such cascades to the structure and stability of ecosystems exposed to environmental change. Since many mutualistic interactions link pairs of species relatively tightly, they present a good starting point for these explorations. However, we can be quite certain that the likelihood and severity of coevolutionary cascades will not be fundamentally different when we extend our view to competitive or exploitative ecological interactions.

\subsection{Concluding Comments}

Only recently have mutualisms been subject to the same level of attention from evolutionary biologists as antagonistic interactions have received (Bronstein 2001a). As a result, it is not surprising that our understanding of how they might respond evolutionarily to anthropogenic change remains rudimentary. This is alarming, because mutualisms appear to be both an ecological and evolutionary nexus for the accumulation of diversity within ecosystems. Further studies of the fate of mutualisms in response to environmental change are therefore essential if the goal is to conserve higher units of biological organization.

Both empirical and theoretical studies are needed. On the theoretical side, there is a dire need for more detailed explorations of eco-evolutionary models of the type tentatively introduced and analyzed in this chapter. A better understanding of the adaptive dynamics that result from mutualistic interactions (Section 16.2) will provide crucial insights with which to probe deeper into the corresponding evolutionary and coevolutionary responses to environmental threats (Sections 16.4 and 16.5). Modeling such environmental threats more specifically, rather than merely through their effects on compound parameters (as done here), will be vital to understand the long-term conservation implications of habitat fragmentation, biological invasions, and genetic introgressions. Eventually we will need to consider models that describe complex webs of interactions realistically, to allow us to assess the dangers of both ecological and coevolutionary ripples cascading through entire communities. No doubt, many surprises are still lurking in the intricate interplay of mutualistic, competitive, and exploitative interactions [see, e.g., the so-called Red King effect, whereby slower evolution leads to a greater selective advantage (Bergstrom and Lachmann 2003)]. To the extent feasible, we should anticipate such surprises by means of careful modeling studies, rather than letting them jeopardize expensive and conservation-critical efforts in the field. 
On the empirical side, we need information on where, when, and how mutualistic interactions are under natural selection in the context of anthropogenic change, and what the likely outcomes (increased generalization; partner shifts; extinction?) appear to be. In this regard, it is important to point out that, to date, the large majority of field studies, as well as nearly all the broad conceptual work on the conservation of mutualism, focus on a single type, plant-pollinator mutualisms. Pollination is undoubtedly of critical importance: perhaps $90 \%$ of angiosperms are animal-pollinated, and it has been estimated that half the food we consume is the product of biotic pollination (Buchmann and Nabhan 1996). However, the responses of a variety of other mutualisms critical to community functions are virtually unknown. For example, the health of some entire marine ecosystems, including coral reefs and hydrothermal vents, depends on mutualistic bacterial and algal symbionts, some of which are clearly sensitive to human activities (Smith and Buddemeier 1992; Knowlton 2003). Thus, in seeking a deeper understanding of the evolutionary conservation biology of mutualisms, it will be essential to take a broader natural history perspective than current knowledge allows. 


\section{References}

References in the book in which this chapter is published are integrated in a single list, which appears on pp. 365-410. For the purpose of this reprint, references cited in the chapter have been assembled below.

Abrams PA, Matsuda H \& Harada Y (1993). Evolutionarily unstable fitness maxima and stable fitness minima of continuous traits. Evolutionary Ecology 7:465-487

Ahas R, Aasa A, Menzel A, Fedotova VG \& Scheifinger H (2002). Changes in European spring phenology. International Journal of Climatology 22:1727-1738

Aizen MA \& Feinsinger P (1994). Forest fragmentation, pollination, and plant reproduction in a Chaco dry forest, Argentina. Ecology 75:330-351

Allen-Wardell G, Bernhardt P, Bitner R, Burquez A, Buchmann S, Cane J, Cox PA, Dalton $\mathrm{V}$, Feinsinger P, Ingram M, Inouye D, Jones CE, Kennedy K, Kevan P, Koopowitz H, Medellin R, Medellin-Morales S, Nabhan GP, Pavlik B, Tepedino V, Torchio P \& Walker $S$ (1998). The potential consequences of pollinator declines on the conservation of biodiversity and stability of food crop yields. Conservation Biology 12:8-17

Alonso LE (1998). Spatial and temporal variation in the ant occupants of a facultative ant-plant. Biotropica 30:201-213

Anstett MC, Michaloud G \& Kjellberg F (1995). Critical population size for fig/wasp mutualism in a seasonal environment: effect and evolution of the duration of receptivity. Oecologia 103:453-461

Anstett MC, Hossaert-McKey M \& McKey D (1997a). Modeling the persistence of small populations of strongly interdependent species: Figs and fig wasps. Conservation Biology 11:204-213

Anstett MC, Hossaert-McKey M \& Kjellberg F (1997b). Figs and fig pollinators: Evolutionary conflicts in a coevolved mutualism. Trends in Ecology and Evolution 12:94-99

Anstett MC, Gibernau M \& Hossaert-McKey M (1998). Partial avoidance of female inflorescences of a dioecious fig by their mutualistic pollinating wasps. Proceedings of the Royal Society of London B 265:45-50

Axelrod R \& Hamilton WD (1981). The evolution of cooperation. Science 211:1390-1396

Beattie AJ (1985). The Evolutionary Ecology of Ant-Plant Mutualisms. Cambridge, UK: Cambridge University Press

Bergstrom CT \& Lachmann M (2003). The Red King effect: When the slowest runner wins the coevolutionary race. Proceedings of the National Academy of Sciences of the USA 100:593-598

Bernhard JM, Buck KR, Farmer MA \& Bowser SS (2000). The Santa Barbara Basin is a symbiosis oasis. Nature 403:77-80

Bond WJ (1994). Do mutualisms matter? Assessing the impact of pollinator and dispersal disruption on plant extinction. Philosophical Transactions of the Royal Society of London B 344:83-90

Bond WJ (1995). Assessing the risk of plant extinction due to pollinator and disperser failure. In Extinction Rates, eds. Lawton JH \& May RM, pp. 174-191. Oxford, UK: Oxford University Press

Bond W \& Slingsby P (1984). Collapse of an ant-plant mutualism: The Argentine ant (Iridomyrmex humilis) and myrmecochorous Proteaceae. Ecology 65:1031-1037

Bronstein JL (1992). Seed predators as mutualists: Ecology and evolution of the fig/pollinator interaction. In Insect-Plant Interactions, Volume IV, ed. Bernays E, pp. 144. Boca Raton, FL, USA: CRC Press 
Bronstein JL (1994). Our current understanding of mutualism. Quarterly Review of Biology 69:31-51

Bronstein JL (1995). The plant/pollinator landscape. In Mosaic Landscapes and Ecological Processes, eds. Fahrig L, Hansson L \& Merriam G, pp. 256-288. New York, NY, USA: Chapman and Hall

Bronstein JL (2001a). Mutualisms. In Evolutionary Ecology: Perspectives and Synthesis, eds. Fox C, Fairbairn D \& Roff D, pp. 315-330. Oxford, UK: Oxford University Press

Bronstein JL (2001b). The exploitation of mutualisms. Ecology Letters 4:277-287

Bronstein JL \& Hossaert-McKey M (1995). Hurricane Andrew and a Florida fig pollination mutualism: Resilience of an obligate interaction. Biotropica 27:373-381

Bronstein JL, Gouyon PH, Gliddon C, Kjellberg F \& Michaloud G (1990). Ecological consequences of flowering asynchrony in monoecious figs: A simulation study. Ecology 71:2145-2156

Brooks JL \& Dodson SI (1965). Predation, body size, and composition of plankton. Science 150:28-35

Brooks WR \& Rittschof D (1995). Chemical detection and host selection by the symbiotic crab Porcellana sayana. Invertebrate Biology 114:180-185

Brown BJ, Mitchell RJ \& Graham SA (2002). Competition for pollination between an invasive species (purple loosestrife) and a native congener. Ecology 83:2328-2336

Buchmann SL \& Nabhan GP (1996). The Forgotten Pollinators. Washington, DC, USA: Island Press

Bull JJ \& Rice WR (1991). Distinguishing mechanisms for the evolution of cooperation. Journal of Theoretical Biology 149:63-74

Callaway RM \& Walker LR (1997). Competition and facilitation: A synthetic approach to interactions in plant communities. Ecology 78:1958-1965

Carroll SP, Klassen SP \& Dingle H (1998). Rapidly evolving adaptations to host ecology and nutrition in the soapberry bug. Evolutionary Ecology 12:955-968

Christensen KM, Whitham TG \& Balda RP (1991). Discrimination among pinyon pine trees by Clark's nutcrackers: Effects of cone crop size and cone characters. Oecologia 86:402-407

Christian CE (2001). Consequences of a biological invasion reveal the importance of mutualism for plant communities. Nature 413:635-639

Cohen AS (1994). Extinction in ancient lakes: Biodiversity crises and conservation 40 years after JL Brooks. Archiv für Hydrobiologie, Beiheft, Ergebnisse der Limnologie 44:451-479

Cole FR, Madeiros AC, Loope LL \& Zuehlke WW (1992). Effects of the Argentine ant on arthropod fauna of Hawaiian high-elevation shrubland. Ecology 73:1313-1322

Compton SG \& McCormack G (1999). The Pacific Banyan in the Cook Islands: Have its pollination and seed dispersal mutualisms been disrupted, and does it matter? Biodiversity and Conservation 8:1707-1715

Czech B \& Krausman PR (1997). Distribution and causation of species endangerment in the United States. Science 277:1116-1117

Dayan T \& Simberloff D (1994). Character displacement, sexual dimorphism, and morphological variation among British and Irish mustelids. Ecology 75:1063-1073

Després L \& Jaeger N (1999). Evolution of oviposition strategies and speciation in the globeflower flies Chiastocheta spp. (Anthomyiidae). Journal of Evolutionary Biology 12:822-831 
Diaz S (1996). Effects of elevated $\mathrm{CO}_{2}$ at the community level mediated by root symbionts. Plant and Soil 187:309-320

Dieckmann U \& Law R (1996). The dynamical theory of coevolution: A derivation from stochastic ecological processes. Journal of Mathematical Biology 34:579-612

Dodd ME, Silvertown J \& Chase MW (1999). Phylogenetic analysis of trait evolution and species diversity variation among angiosperm families. Evolution 53:732-744

Doebeli M \& Knowlton N (1998). The evolution of interspecific mutualisms. Proceedings of the National Academy of Sciences of the USA 95:8676-8680

Douglas AE (1994). Symbiotic Interactions. New York, NY, USA: Oxford University Press

Dressler RL (1981). The Orchids: Natural History and Classification. Cambridge, MA, USA: Harvard University Press

Dugatkin LA (1997). Cooperation Among Animals: An Evolutionary Perspective. New York, NY, USA: Oxford University Press

Dunne JA, Harte J \& Taylor KJ (2003). Subalpine meadow flowering phenology responses to climate change: Integrating experimental and gradient methods. Ecological Monographs 73:69-86

Dwyer G, Levin SA \& Buttel L (1990). A simulation model of the population dynamics and evolution of myxomatosis. Ecological Monographs 60:423-447

Elliott JK, Elliott JM \& Mariscal RN (1995). Host selection, location, and association behaviors of anemonefishes in field settlement experiments. Marine Biology 122:377389

Erhardt A \& Rusterholz HP (1997). Effects of elevated $\mathrm{CO}_{2}$ on flowering phenology and nectar production. Acta Oecologica 18:249-253

Ferrière R, Bronstein JL, Rinaldi S, Law R \& Gauduchon M (2002). Cheating and the evolutionary stability of mutualism. Proceedings of the Royal Society of London B 269:773780

Fitter AH \& Fitter RSR (2002). Rapid changes in flowering time in British plants. Science 296:1689-1691

Fritts TH \& Rodda GH (1998). The role of introduced species in the degradation of island ecosystems: A case history of Guam. Annual Review of Ecology and Systematics 29:113-140

Geritz SAH, Metz JAJ, Kisdi E \& Meszéna G (1997). Dynamics of adaptation and evolutionary branching. Physics Review Letters 78:2024-2027

Gibernau M \& Hossaert-McKey M (1998). Are olfactory signals sufficient to attract fig pollinators? Ecoscience 5:306-311

Goverde M, Schweizer K, Baur B \& Erhardt A (2002). Small-scale habitat fragmentation effects on pollinator behaviour: Experimental evidence from the bumblebee Bombus veteranus on calcareous grasslands. Biological Conservation 104:293-299

Groom MJ (1998). Allee effects limit population viability of an annual plant. The American Naturalist 151:487-496

Hackney EE \& McGraw JB (2001). Experimental demonstration of an Allee effect in American ginseng. Conservation Biology 15:129-136

Harrison RD (2000). Repercussions of El Niño: Drought causes extinction and the breakdown of mutualism in Borneo. Proceedings of the Royal Society of London B 267:911915

Helander ML, Neuvonen S \& Ranta H (1996). Natural variation and effects of anthropogenic environmental changes on endophytic fungi in trees. In Endophytic Fungi in 
Grasses and Woody Plants, eds. Redin SC \& Carris ML, pp. 197-207. Saint Paul, MN, USA: APS Press

Herre EA, Knowlton N, Mueller UG \& Rehner SA (1999). The evolution of mutualisms: Exploring the paths between conflict and cooperation. Trends in Ecology and Evolution 14:49-53

Hofbauer J \& Sigmund K (1990). Adaptive dynamics and evolutionary stability. Applied Mathematics Letters 3:75-79

Holland JN \& DeAngelis DL (2001). Population dynamics and the ecological stability of obligate pollination mutualisms. Oecologia 126:575-586

Holland JN, DeAngelis DL \& Bronstein JL (2002). Population dynamics of mutualism: Functional responses of benefits and costs. The American Naturalist 159:231-244

Holway DA (1998). Effect of Argentine ant invasions on ground-dwelling arthropods in northern California riparian woodlands. Oecologia 116:252-258

Horvitz CC \& Schemske DW (1990). Spatiotemporal variation in insect mutualists of a neotropical herb. Ecology 71:1085-1097

Inouye DW, Morales MA \& Dodge GJ (2002). Variation in timing and abundance of flowering by Delphinium barbeyi Huth (Ranunculaceae): The roles of snowpack, frost, and La Niña, in the context of climate change. Oecologia 130:543-550

Janzen DH \& Martin P (1982). Neotropical anachronisms: What the gomphotheres ate. Science 215:19-27

Jordano P (1994). Spatial and temporal variation in the avian-frugivore assemblage of Prunus mahaleb: Patterns and consequences. Oikos 71:479-491

Jules ES \& Rathcke BJ (1999). Mechanisms of reduced Trillium recruitment along edges of old-growth forest remnants. Conservation Biology 13:784-793

Karban R (1986). Interspecific competition between folivorous insects on Erigeron glaucus. Ecology 67:1063-1072

Kareiva PM, Kingsolver JG \& Huey RB, eds. (1993). Biotic Interactions and Global Change. Sunderland, MA, USA: Sinauer Associates Inc.

Kearns CA, Inouye DW \& Waser NM (1998). Endangered mutualisms: The conservation of plant-pollinator interactions. Annual Review of Ecology and Systematics 29:83-112

Khadari B, Gibernau M, Anstett MC, Kjellberg F \& Hossaert-McKey M (1995). When figs wait for pollinators: The length of fig receptivity. American Journal of Botany 82:992999

Kinzie RAI (1992). Predation by the introduced carnivorous snail Euglandina rosea (Ferussac) on endemic aquatic lymnaeid snails in Hawaii. Biological Conservation 60:149155

Kisdi E (1999). Evolutionary branching under asymmetric competition. Journal of Theoretical Biology 197:149-162

Kjellberg F \& Valdeyron G (1990). Species-specific pollination: A help or a limitation to range extension? In Biological Invasions in Europe and the Mediterranean Basin, eds. diCastri F \& Hansen AJ, pp. 371-378. The Hague, Netherlands: Dr W Junk Publishers

Knowlton N (2003). Microbial mutualisms on coral reefs: The host as habitat. The American Naturalist $\mathbf{S 1 6 1}$. In press

Lappalainen JH, Koricheva J, Helander ML \& Haukioja E (1999). Densities of endophytic fungi and performance of leafminers (Lepidoptera: Eriocraniidae) on birch along a pollution gradient. Environmental Pollution 104:99-105

Law R, Marrow P \& Dieckmann U (1997). On evolution under asymmetric competition. Evolutionary Ecology 11:485-501 
Law R, Bronstein JL \& Ferrière RG (2001). On mutualists and exploiters: Plant-insect coevolution in pollinating seed-parasite systems. Journal of Theoretical Biology 212:373389

Lawrey JD \& Hale JME (1979). Lichen growth responses to stress induced by automobile exhaust pollution. Science 204:423-424

Lawton JH (1981). Asymmetrical competition in insects. Nature 289:793-795

Lee TN \& Stone AA (1998). Pollinator preferences and the persistence of crop genes in wild radish populations (Raphanus raphanistrum, Brassicaceae). American Journal of Botany 85:333-339

Lopez-Vaamonde C, Rasplus JY, Weiblen GD \& Cook JM (2001). Molecular phylogenies of fig wasps: Partial cocladogenesis of pollinators and parasites. Molecular Phylogenetics and Evolution 21:55-71

Lord JM (1991). Pollination and seed dispersal in Freycinetia baueriana, a dioecious liane that has lost its bat pollinator. New Zealand Journal of Botany 29:83-86

Louda SM, Kendall D, Connor J \& Simberloff D (1997). Ecological effects of an insect introduced for the biological control of weeds. Science 277:1088-1090

Martin PS \& Klein RG (1984). Quaternary Extinctions: A Prehistoric Revolution. Tucson, AZ, USA: University of Arizona Press

Matsuda H \& Abrams P (1994). Plant-herbivore interactions and theory of coevolution. Plant Species Biology 9:155-161

May RM (1976). Models for two interacting populations. In Theoretical Ecology: Principles and Applications, ed. May RM, pp. 49-70. Philadelphia, PA, USA: Saunders

McKey D (1989). Population biology of figs: Applications for conservation. Experientia 45:661-673

Metz JAJ, Nisbet RM \& Geritz SAH (1992). How should we define fitness for general ecological scenarios? Trends in Ecology and Evolution 7:198-202

Mitchell RJ (1994). Effects of floral traits, pollinator visitation, and plant size on Ipomopsis aggregata fruit production. The American Naturalist 143:870-889

Morris WF, Bronstein JL \& Wilson WG (2003). Three-way coexistence in obligate mutualist-exploiter interactions: The potential role of competition. The American Naturalist 161:860-875

Moulton MP (1993). The all-or-none pattern in introduced Hawaiian passeriformes: The role of competition sustained. The American Naturalist 141:105-119

Nadel H, Frank JH \& Knight JRJ (1992). Escapees and accomplices: The naturalization of exotic Ficus and their associated faunas in Florida. Florida Entomologist 75:29-38

Nason JD, Herre EA \& Hamrick JL (1998). The breeding structure of a tropical keystone plant resource. Nature 391:685-687

Nilsson LA (1992). Orchid pollination biology. Trends in Ecology and Evolution 7:255259

Noë R \& Hammerstein P (1995). Biological markets. Trends in Ecology and Evolution 10:336-339

Pellmyr O \& Leebens-Mack J (1999). Forty million years of mutualism: Evidence for Eocene origin of the yucca-yucca moth association. Proceedings of the National Academy of Sciences of the USA 96:9178-9183

Pemberton RW \& Irving DW (1990). Elaiosomes on weed seeds and the potential for myrmecochory in naturalized plants. Weed Science 38:615-619 
Primack RB (1985). Patterns of flowering phenology in communities, populations, individuals, and single flowers. In Population Structure of Vegetation, ed. White J, pp. 571-594. Dordrecht, Netherlands: Kluwer Academic Publishers

Rasplus J-Y (1996). The one-to-one species-specificity of the Ficus-Agaonine mutualism: How casual? In The Biodiversity of African Plants, eds. van der Maesen LJG, van der Burgt XM \& van Medenbach de Rooy JM, pp. 639-649. Wageningen, Netherlands: Kluwer Academic Publishers

Richardson DM, Allsopp N, D’Antonio C, Milton SJ \& Rejmánek M (2000). Plant invasions: The role of mutualisms. Biological Reviews 75:65-93

Roberts G \& Sherratt TN (1998). Development of cooperative relationships through increasing investment. Nature 394:175-179

Savidge JA (1987). Extinction of an island forest avifauna by an introduced snake. Ecology 68:660-668

Schofield EK (1989). Effects of introduced plants and animals on island vegetation: Examples from the Galapagos archipelago. Conservation Biology 3:227-238

Shanahan M, So S, Compton S \& Corlett R (2001a). Fig-eating by vertebrate frugivores: A global review. Biological Reviews 76:529-572

Shanahan M, Harrison RD, Yamuna R, Boen W \& Thornton IWB (2001b). Colonization of an island volcano, Long Island, Papua New Guinea, and an emergent island, Motmot, in its caldera lake. V. Colonization by figs (Ficus spp.), their dispersers and pollinators. Journal of Biogeography 28:1365-1377

Simberloff D (1981). Community effects of introduced species. In Biotic Crises in Ecological and Evolutionary Time, ed. Nitecki M, pp. 53-81. New York, NY, USA: Academic Press

Simberloff D \& von Holle B (1999). Positive interactions of nonindigenous species: Invasional meltdown? Biological Invasions 1:21-32

Singer MC \& Thomas CD (1996).Evolutionary responses of a butterfly metapopulation to human- and climate-caused environmental variation. The American Naturalist 148:9-39

Singer MC, Thomas CD \& Parmesan C (1993). Rapid human-induced evolution of insecthost associations. Nature 366:681-683

Smith JF (2001). High species diversity in fleshy-fruited tropical understory plants. The American Naturalist 157:646-653

Smith SV \& Buddemeier RW (1992). Global change and coral reef ecosystems. Annual Review of Ecology and Systematics 23:89-118

Smith TB, Freed LA, Lepson JK \& Carothers JH (1995). Evolutionary consequences of extinctions in populations of a Hawaiian honeycreeper. Conservation Biology 9:107113

Snow AA \& Palma PM (1997). Commercialization of transgenic plants: Potential ecological risks. Bioscience 47:86-96

Soberon Mainero J \& Martinez del Rio C (1985). Cheating and taking advantage in mutualistic associations. In The Biology of Mutualism, ed. Boucher DH, pp. 192-216. New York, NY, USA: Oxford University Press

Staddon PL \& Fitter AH (1998). Does elevated atmospheric carbon dioxide affect arbuscular mycorrhizas? Trends in Ecology and Evolution 13:455-458

Stanton ML (2003). Interacting guilds: Moving beyond the pairwise perspective on mutualisms. The American Naturalist 162:S10-S23

Steadman DW (1995). Prehistoric extinctions of Pacific Island birds: Biodiversity meets zooarcheology. Science 267:1123-1131 
Takabayashi J \& Dicke M (1996). Plant-carnivore mutualism through herbivore-induced carnivore attractants. Trends in Plant Sciences 1:109-113

Temple SA (1977). Plant-animal mutualism: Coevolution with dodo leads to near extinction of plant. Science 197:885-886

Thomas RB, Richter DD, Ye H, Heine PR \& Strain BR (1991). Nitrogen dynamics and growth of seedlings of an $\mathrm{N}$-fixing tree (Gliricidia sepium (Jacq.) Walp.) exposed to elevated atmospheric carbon dioxide. Oecologia 88:415-421

Thompson JN (1994). The Coevolutionary Process. Chicago, IL, USA: University of Chicago Press

Thompson JN (1996). Evolutionary ecology and the conservation of biodiversity. Trends in Ecology and Evolution 11:300-303

Thomson JD, Plowright RC \& Thaler GR (1985). Matacil insecticide spraying, pollinator mortality, and plant fecundity in New Brunswick forests. Canadian Journal of Botany 63:2056-2061

Wall DH \& Moore JC (1999). Interactions underground: Soil biodiversity, mutualism, and ecosystem processes. BioScience 49:109-117

Ware AB, Kaye PT, Compton SG \& Noort SV (1993). Fig volatiles: Their role in attracting pollinators and maintaining pollinator specificity. Plant Systematics and Evolution 186: $147-156$

Waser NM, Chittka L, Price MV, Williams NM \& Ollerton J (1996). Generalization in pollination systems, and why it matters. Ecology 77:1043-1060

Washitani I (1996). Predicted genetic consequences of strong fertility selection due to pollinator loss in an isolated population of Primula sieboldii. Conservation Biology 10:59-64

Wcislo WT \& Cane JH (1996). Floral resource utilization by solitary bees (Hymenoptera: Apoidea) and exploitation of their stored food by natural enemies. Annual Review of Entomology 41:257-286

Weiblen GD (2002). How to be a fig wasp. Annual Review of Entomology 47:299-330

Williamson M (1996). Biological Invasions. New York, NY, USA: Chapman and Hall

Williamson M \& Brown KC (1986). The analysis and modelling of British invasions. Philosophical Transactions of the Royal Society of London B 314:505-522

Wilson EO (1992). The Diversity of Life. New York, NY, USA: WW Norton \& Company

Wilson WG, Morris WF \& Bronstein JL (2003). Coexistence of mutualists and exploiters on spatial landscapes. Ecological Monographs 73:397-413

Witmer MC \& Cheke AS (1991). The dodo and the tambalacoque tree: An obligate mutualism reconsidered. Oikos 61:133-137

Wolin CL (1985). The population dynamics of mutualistic systems. In The Biology of Mutualism, ed. Boucher DH, pp. 248-269. New York, NY, USA: Oxford University Press

Young TP, Stubblefield CH \& Isbell LA (1997). Ants on swollen-thorn acacias: Species coexistence in a simple system. Oecologia 109:98-107

Yu DW (2001). Parasites of mutualisms. Biological Journal of the Linnean Society 72:S29S46 